\title{
Microstructure and mechanical behaviour of the isothermally forged Ti-6Al-7Nb alloy
}

\author{
P F Barbosa and S T Button
}

School of Mechanical Engineering, State University of Campinas, Brazil

\begin{abstract}
The mechanical properties of the Ti-6Al-7Nb alloy, used to manufacture high-strength prostheses, are highly dependent on its microstructure. This work presents the microstructural changes of this alloy under isothermal hot working. It is shown that microstructure is strongly affected by strain rate, temperature and strain. The possible precipitation of intermetallic phases is also evaluated. To define the best processing conditions, compression tests were performed at temperatures varying from 750 to $1030{ }^{\circ} \mathrm{C}$ and deformation speeds of $0.01,0.1$ and $1 \mathrm{~mm} / \mathrm{s}$. Tests were carried out in the $\alpha+\beta$ and $\beta$ phase regions. Experimental results showed that the best microstructure (recrystallized with equiaxial refined white $\alpha$ grains and acicular dark grains within a $\beta$-transformed matrix) was obtained in tests at $950{ }^{\circ} \mathrm{C}$ and $0.01 \mathrm{~mm} / \mathrm{s}$.
\end{abstract}

Keywords: Titanium alloys, microstructural changes, isothermal forging

\section{NOTATION}

$e$ engineering strain $[\mathrm{mm} / \mathrm{mm}]$

$v$ deformation speed $[\mathrm{mm} / \mathrm{s}]$

$\sigma_{e}$ engineering stress $[\mathrm{MPa}]$

$\sigma_{r}$ true stress $[\mathrm{MPa}]$

\section{INTRODUCTION AND OBJECTIVES}

Titanium alloys have been clinically applied since the 1970s when surgical implants were made with the high-strength Ti-6Al-4V alloy.

The Ti-6Al-7Nb alloy was introduced into clinical use in the mid 1980s as a substitute for Ti$6 \mathrm{Al}-4 \mathrm{~V}$, since niobium is more biocompatible and cheaper than vanadium. The vanadium oxide $\mathrm{VO}_{2}$, generated by passivation of the metal surface, is thermodynamically unstable and some vanadium could be released in human body and cause toxic effects [1]. Semlitsch et al. [2] showed the mechanical properties obtained in trial runs for many Ti-6Al alloys with niobium and tantalum as substitutes for vanadium and concluded that $\mathrm{Ti}$ $6 \mathrm{Al}-7 \mathrm{~b}$ showed the best workability and mechanical properties.

The MS was received on 1 September 1999 and was accepted after revision for publication on 21 December 1999.

*Corresponding author: Metal Forming Laboratory, Department of Materials Engineering, School of Mechanical Engineering, State University of Campinas, DEMA-FEMUNICAMP, CP 6122, 13083-970, Campinas, SP, Brazil.
Ti-6Al-7Nb alloy was developed to achieve the following objectives [3]:

- a dense and stable passive surface layer with the presence of all alloying elements;

- high resistance to corrosion;

- $\alpha+\beta$ grain structure with the possibility of superplastic deformability;

- mechanical properties comparable with those of the high-strength, wrought Ti6Al-4V alloy;

- economical production of semifinished material and of implant components.

These alloys can be cast, hot rolled and hot forged, so products of many shapes can be manufactured like components for knee, wrist, and total hip prostheses. Figure 1 shows a total hip prosthesis with an acetabular cup made of UHMW polyethylene, a femoral head made of zirconia, and a Ti-6Al-7Nb forged stem.

These alloys have great mechanical strength and high resistance to corrosion and are superplastic when hot worked. These properties can be controlled with thermomechanical and chemical treatments, resulting in high strength/weight rates [4-7]. Table 1 shows some mechanical properties of the globular Ti$6 \mathrm{Al}-7 \mathrm{Nb}$ alloy hot-forged at temperatures below $1000{ }^{\circ} \mathrm{C}$ and vacuum-annealed at $700{ }^{\circ} \mathrm{C}$. As observed in the table these properties are superior to those recommended in ISO 5832-3 specifications for the Ti-6Al-4V wrought alloy. 


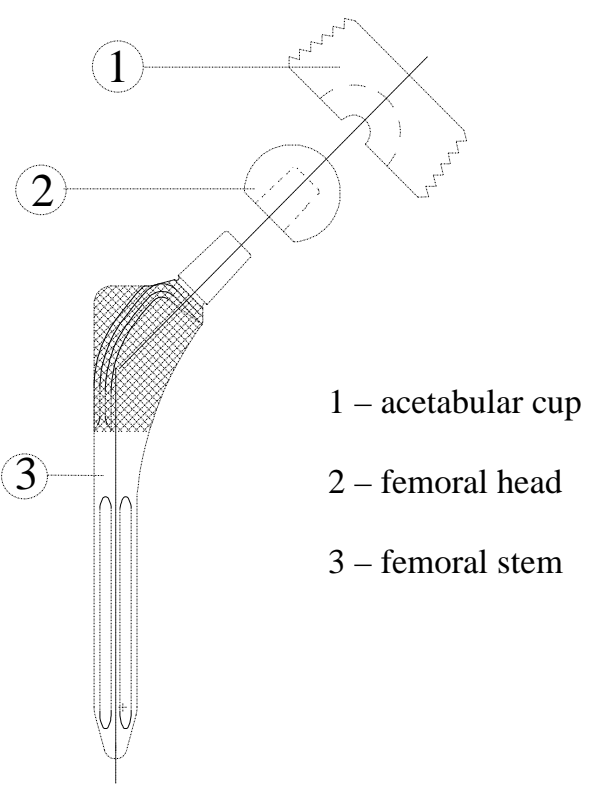

Fig. 1 Components of a total hip prosthesis.

Table 1 Mechanical properties of the Ti-6Al-7Nb as hot-forged [1]

\begin{tabular}{ccc}
\hline $\begin{array}{c}\text { Mechanical } \\
\text { properties }\end{array}$ & $\begin{array}{c}\text { ISO 5832-3 } \\
\text { specifications }\end{array}$ & $\begin{array}{c}\text { Ti-6Al-7Nb hot- } \\
\text { forged }\end{array}$ \\
\hline $\begin{array}{c}\text { Young's modulus } \\
\text { [MPa] }\end{array}$ & - & 110000 \\
$\begin{array}{c}\text { Yield strength } \\
0.2 \%\end{array}$ & $\operatorname{Min} 800$ & $900-1000$ \\
$\begin{array}{c}\text { Ultimate tensile } \\
\text { strength }\end{array}$ & Min 900 & $1000-1100$ \\
$\begin{array}{c}\text { Elongation [\%] } \\
\text { Reduction of area }\end{array}$ & Min 10 & $10-15$ \\
$\begin{array}{c}\text { Rotating bending } 25 \\
\text { fatigue strength }\end{array}$ & Min 450 & $15-45$ \\
& & \\
\end{tabular}

Ti-6Al-7Nb and Ti-6Al-4V are $\alpha+\beta$ alloys whose mechanical properties are susceptible to prior thermomechanical treatments, which show more microstructures than the $\alpha$ alloys and are controlled by strain, strain rate and work temperature. The transformation temperature $\alpha+\beta / \beta$ is between 1010 and $1020{ }^{\circ} \mathrm{C}$ [8]. Commonly, $\alpha+\beta$ alloys are hot worked at temperatures under $\beta$ transus. At this temperature all of the $\alpha$ microstructure is transformed into $\beta$.

The $\alpha+\beta$ alloys have alloy elements which stabilize the $\alpha$ and $\beta$ phases and increase the range of temperatures where the $\alpha+\beta$ microstructure can be found, even below room temperature as observed in figure 2 that shows the $\mathrm{Ti}-\mathrm{Al}$ and $\mathrm{Ti}-\mathrm{Nb}$ phase diagrams assessed by J.L. Murray $[\mathbf{9 , 1 0 ]}$.

When hot worked these alloys show as a result microstructures with large $\beta$ grains wherein $\alpha$ grains grow during cooling. The volume fraction of $\alpha / \beta$ is dependent on working temperature [11].

The $\alpha+\beta$ microstructure is superplastic when hot worked, being suitable for isothermal forging of complex shapes like components for the aerospace industry, turbine blades and surgical implants. Nearnet-shape parts are manufactured by isothermal forging with low strain rates $\left(0.005 \mathrm{~s}^{-1}\right)$ typical of hydraulic presses.

The main objective of this work is to study how work temperature and deformation speed influence the microstructure and the workability of the alloy. Compression tests were carried out to define the best processing conditions to be used in the isothermal forging of femoral stems used in surgical implants.

\section{EXPERIMENTAL METHODS AND MATERIALS}

Cylindrical specimens were cut off from a hot rolled bar with a $17 \mathrm{~mm}$ gauge diameter. This bar from IMI Titanium Ltd. (IMI 367 alloy) had been previously annealed at $750{ }^{\circ} \mathrm{C}$ for one hour and aircooled and had the chemical composition shown in table 2 and the mechanical properties shown in table 3 [12].

The specimens were machined to cylinders $12 \mathrm{~mm}$ long and $8 \mathrm{~mm}$ in diameter. These cylinders were deformed by isothermal compression in a universal testing machine at temperatures of 750 , 850, 950 and $1030{ }^{\circ} \mathrm{C}$ and constant deformation speeds of $1.0,0.1$ and $0.01 \mathrm{~mm} / \mathrm{s} \mathrm{[13].} \mathrm{To} \mathrm{simulate}$ the processing conditions present in industrial hot forging no lubricant was used in all the tests.

During the tests the specimens were heated with the compression dies in an electrical furnace without atmospheric treatment for a soaking time of 10 minutes at all temperatures. Heating time varied from 10 to 25 minutes depending on the strain in each test, defined by the maximum compression load limited to $19600 \mathrm{~N}$. The tests were replicated three times. Once deformed, the specimens were removed from the furnace, air cooled to reproduce forging conditions, and finally, prepared for micrographic and X-ray diffraction analyses. 

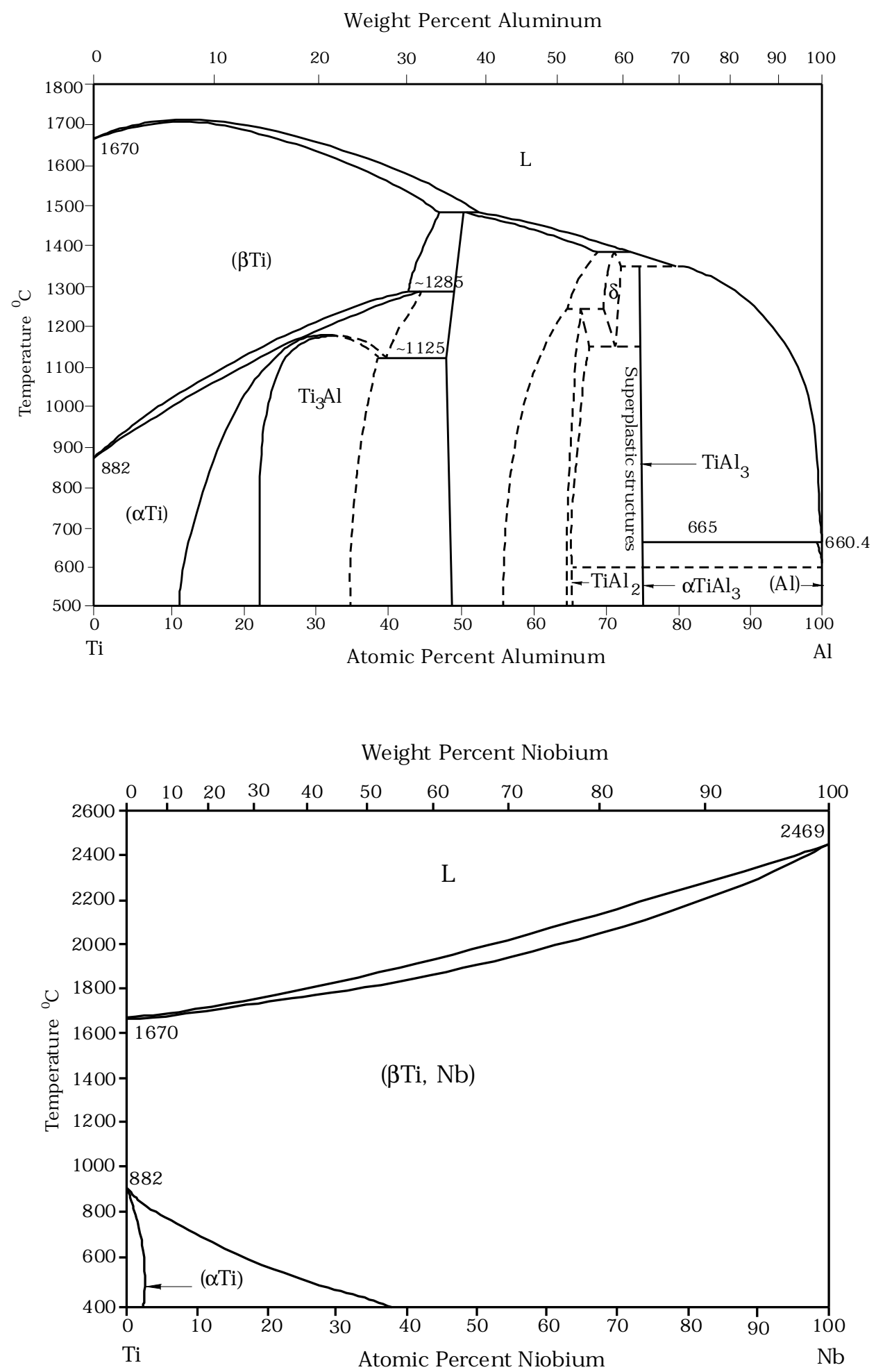

Fig. 2 Phase diagrams: (a) Ti-Al system [9] and (b) Ti-Nb system [10]

Table 2 Chemical composition of the alloy as received [9]

\begin{tabular}{|l|c|c|c|c|c|c|c|c|c|c|}
\hline Element & $\mathrm{C}$ & $\mathrm{N}$ & $\mathrm{O}$ & $\mathrm{Al}$ & $\mathrm{Nb}$ & $\mathrm{Ta}$ & $\mathrm{Fe}$ & $\mathrm{H}$ & $\mathrm{V}$ & $\mathrm{Ti}$ \\
\hline Weight $\%$ & 0.015 & 0.0087 & 0.190 & 6.280 & 7.235 & $<0.50$ & 0.190 & 0.001 & - & basis \\
\hline
\end{tabular}


Table 3 Mechanical properties of the as-received alloy [9]

\begin{tabular}{cccc}
\hline $\begin{array}{c}\text { Yield } \\
\text { strength }\end{array}$ & $\begin{array}{c}\text { Tensile } \\
\text { strength }\end{array}$ & $\begin{array}{c}\text { Percent } \\
\text { elongation }\end{array}$ & $\begin{array}{c}\text { Percent } \\
\text { area } \\
\text { reduction }\end{array}$ \\
\hline $928 \mathrm{MPa}$ & $1038 \mathrm{MPa}$ & $14.5 \%$ & $49 \%$ \\
\hline
\end{tabular}

The material as received and the deformed specimens were cut off at the longitudinal section, pressed in Bakelite for 20 minutes at $220{ }^{\circ} \mathrm{C}$ and abraded and polished in sequence with $6 \mu \mathrm{m}$ diamond paste, then with $\mathrm{Cr}_{3}$ and $\mathrm{Al}_{2} \mathrm{O}_{3}$ solution (1 $\mu \mathrm{m}$ of granulometry) and finally with colloidal silica suspension with a $0.01 \mu \mathrm{m}$ granulometry. To analyse the microstructure the samples were etched for 5 seconds with Kroll solution $\left(\mathrm{HNO}_{3}-5 \mathrm{ml}, \mathrm{HF}-10\right.$ $\mathrm{ml}$ and distilled water $-85 \mathrm{ml})$.

\section{RESULTS AND DISCUSSION}

Barrelling was present in all deformed specimens, and increased as temperature and speed deformation were increased. Longitudinal sections of these specimens showed a "X" aspect, typical of cylinders compressed under sliding friction conditions. Three regions are present denoting heterogeneity of deformation, one region near the dies surfaces with low deformation due to the sticking effect, a second near the free surface with high deformation, and the third region represented by the "X" between the other two regions, presenting high shear stresses [14].

This inhomogeneous deformation causes difficulties in obtaining and interpreting flow stress asymmetry observations and microstructural changes, specially at large plastic strains [15]. To make the microstructural analysis uniform for all deformed specimens, micrographs were always taken from the region near the free surface except when mentioned in the analysis.

The micrograph of the material as received (figure 3) shows an $\alpha+\beta$ microstructure, deformed and elongated in the rolling direction, with white $\alpha$ grains and dark acicular $\alpha$ grains within a $\beta$ transformed matrix.

Table 4 shows the peaks ( $2 \theta$ angles) obtained for this material. The crystallographic planes and phases identified with these peaks are similar to those found in the Ti-6Al-4V alloy [16].

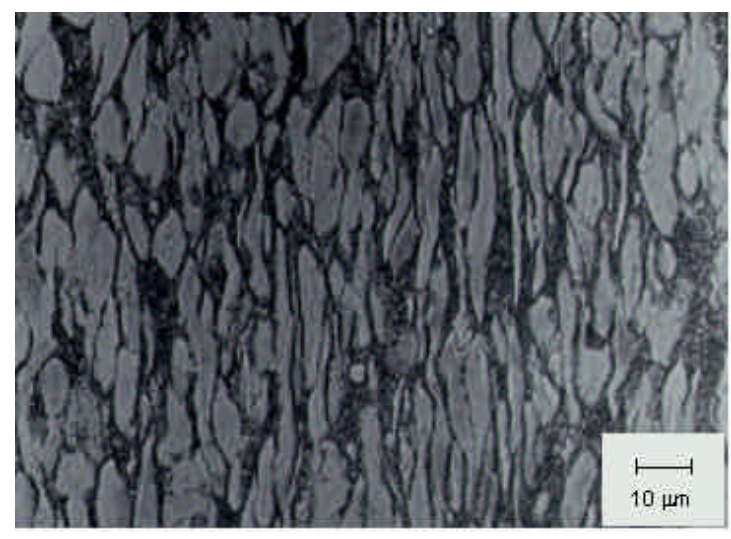

Fig. 3 Micrograph of the initial material as received: longitudinal section.

The deformed specimens were also analysed by diffractometry, but it was difficult to identify the $\beta$ phase peaks because they appear near $\alpha$ phase peaks, as seen in table 4 . There were some variations among the $2 \theta$ angles, probably due to different strains for each specimen. With the diffractograms it is possible to state that no different phase had precipitated when the specimens were deformed. Table 5 shows the $2 \theta$ diffraction angles with the respective crystallographic planes of the deformed specimens.

\subsection{Tests at $750{ }^{\circ} \mathrm{C}$}

Specimens deformed at $750{ }^{\circ} \mathrm{C}$ showed a deformed microstructure with $\alpha$ grains and $\alpha$-acicular within a $\beta$ matrix at the boundaries of $\alpha$ grains. Engineering strain varied from 9 to $62 \%$ and no internal or superficial defects were observed, denoting good workability. Specimens with engineering strains of 9 and $15 \%$ and speeds of 0.01 and $0.1 \mathrm{~mm} / \mathrm{s}$ showed the same microstructure as that of the initial material. On the surface the elongation of the grain changed direction due to deformation. The boundaries of $\alpha$ grains became sharper.

Table 4 Diffraction results for the $2 \theta$ angles material as received

\begin{tabular}{ccc}
\hline $2 \theta$ & Probable crystallographic plane & Phase \\
\hline 30.0 & - & - \\
34.6 & $(100)$ & $\alpha$ \\
37.6 & $(002)$ & $\alpha$ \\
38.4 & $(110)$ & $\beta$ \\
39.5 & $(101)$ & $\alpha$ \\
52.4 & $(102)$ & $\alpha$ \\
62.6 & $(110)$ & $\alpha$ \\
70.0 & $(103)$ & $\alpha$ \\
76.0 & $(112)$ & $\alpha$ \\
\hline
\end{tabular}


With the increase in engineering strain $(40 \%$ and $0.1 \mathrm{~mm} / \mathrm{s}$ ), microstructure changed and most of the grains were elongated and reoriented. Only the central region of the specimens kept original microstructure. Some small and well-defined grains were observed, denoting the beginning of a recrystallized structure.

With the high engineering strain $(62 \%$ and $0.01 \mathrm{~mm} / \mathrm{s}$ ) the specimen showed a strongly deformed microstructure, and it was difficult to observe grain boundaries. The recrystallization was probably not too fast and grains became refined and distorted (figure 4).

\subsection{Tests at $850{ }^{\circ} \mathrm{C}$}

Specimens deformed at $850{ }^{\circ} \mathrm{C}$ showed different microstructures depending on engineering strain applied, as observed with specimens worked at 750 ${ }^{\circ} \mathrm{C}$. But at $850^{\circ} \mathrm{C}$ the effect of strain speed was more intense, influencing recrystallization.

With an engineering strain of $4 \%$ and a speed of $1.0 \mathrm{~mm} / \mathrm{s}$ the structure was similar to the material as received. With the same speed and a strain of $58 \%$ different microstructures were observed.

Table 5 Diffraction results for the $2 \theta$ angles - deformed specimens

(First row: temperatures; second row: deformation speed [mm/s]) (-) very low peak intensity

\begin{tabular}{|c|c|c|c|c|c|c|c|c|c|c|c|c|}
\hline \multicolumn{3}{|c|}{750} & \multicolumn{3}{c|}{$\mathbf{8 5 0}{ }^{\circ} \mathbf{C}$} & \multicolumn{3}{c|}{$950{ }^{\circ} \mathbf{C}$} & \multicolumn{3}{c|}{$1030{ }^{\circ} \mathbf{C}$} & \multicolumn{2}{c|}{$\begin{array}{c}\text { (Crystallographic } \\
\text { Planes) - Phases }\end{array}$} \\
\hline $\mathbf{0 . 0 1}$ & $\mathbf{0 . 1}$ & $\mathbf{1 . 0}$ & $\mathbf{0 . 0 1}$ & $\mathbf{0 . 1}$ & $\mathbf{1 . 0}$ & $\mathbf{0 . 0 1}$ & $\mathbf{0 . 1}$ & $\mathbf{1 . 0}$ & $\mathbf{0 . 0 1}$ & $\mathbf{0 . 1}$ & $\mathbf{1 . 0}$ & - \\
\hline 31.2 & 31.2 & - & - & - & - & - & 30.6 & 31.4 & - & - & - & $(100)-\alpha$ \\
\hline 35.5 & 35.5 & 35.8 & 35.6 & 35.7 & 35.8 & 35.5 & 35.0 & 35.7 & 34.8 & 35.5 & 35.5 & $(002)-\alpha$ \\
\hline 38.5 & 38.5 & 38.8 & 38.7 & 38.7 & 38.8 & 38.4 & 38.0 & 38.8 & 38.0 & 38.4 & 38.4 & $(110)-\beta$ \\
\hline 39.2 & 39.2 & 39.3 & 39.2 & 39.3 & 39.4 & 39.0 & 38.8 & 39.4 & - & 39.0 & 39.0 & $(101)-\alpha$ \\
\hline 40.5 & 40.4 & 40.7 & 40.6 & 40.7 & 40.8 & 40.4 & 40.0 & 40.7 & 40.0 & 40.0 & 40.5 & $(102)-\alpha$ \\
\hline 53.2 & 53.2 & 53.4 & 53.3 & 53.4 & 53.4 & 53.0 & 52.8 & 53.4 & 53.1 & 53.2 & 53.2 & $(110)-\alpha$ \\
\hline 63.5 & 63.3 & 63.6 & 63.5 & 63.6 & 63.7 & 63.4 & 63.0 & 63.8 & 63.2 & 63.1 & 63.4 & $(103)-\alpha$ \\
\hline 70.8 & 70.8 & 70.8 & 70.8 & 71.0 & 71.0 & 70.6 & 70.6 & 70.8 & 70.4 & 70.8 & 70.6 & $(112)-\alpha$ \\
\hline 76.5 & 76.6 & 76.8 & 76.6 & 76.8 & 76.8 & 76.6 & 76.4 & 76.8 & 76.1 & 76.5 & - & $(201)-\alpha$ \\
\hline 78.2 & 77.8 & 78.0 & 78.0 & 78.0 & 78.2 & 77.8 & 77.6 & 78.0 & 77.6 & 77.8 & - & $(004)-\alpha$ \\
\hline- & - & - & - & - & - & - & - & - & 82.0 & - & - & $-\alpha$ \\
\hline
\end{tabular}

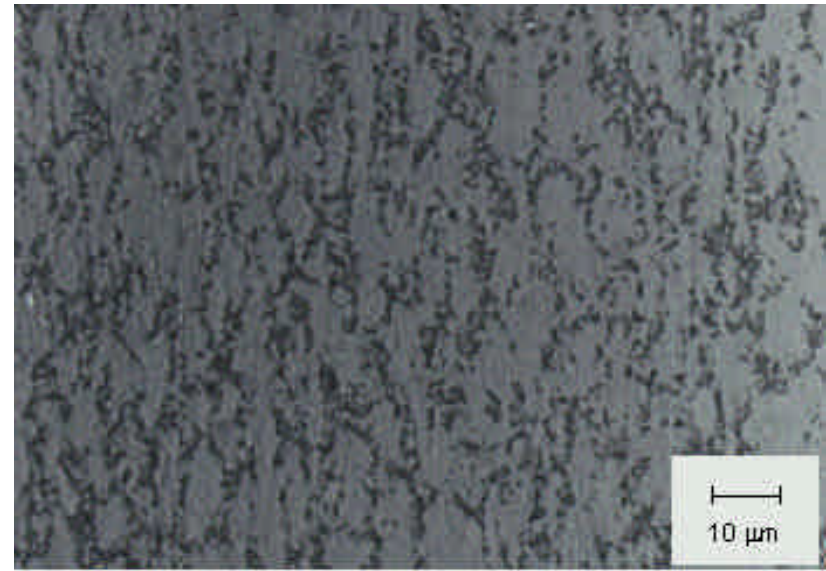

Fig. 4 Micrograph of deformed specimens at $750{ }^{\circ} \mathrm{C}: \mathrm{v}=0.01 \mathrm{~mm} / \mathrm{s}$ and $\mathrm{e}=62 \%$.

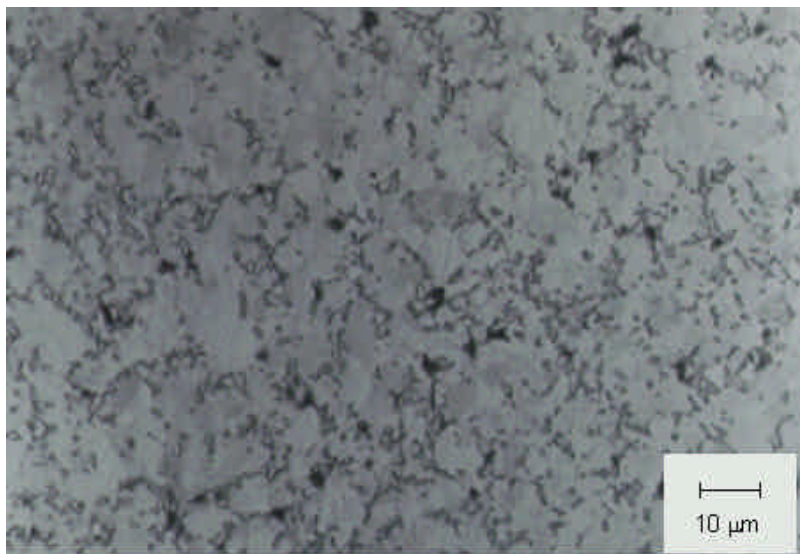

Fig. 5 Micrograph of deformed specimens at $850^{\circ} \mathrm{C}: \mathrm{v}=0.01 \mathrm{~mm} / \mathrm{s}$ and $\mathrm{e}=54 \%$. 
At the periphery (the most deformed region) the structure was oriented and aligned with the direction of the flow, with white $\alpha$ grains and welldefined $\beta$ grains at the boundaries. In the region in contact with the dies (high friction and low deformation) the structure was the same as that of the received material, but the grains were coarser and better defined. The central region showed a recrystallized structure apparently undeformed with equiaxial white $\alpha$ grains surrounded by $\beta$ grains.

The same structure was observed in the specimens deformed with a speed of $0.01 \mathrm{~mm} / \mathrm{s}$ and engineering strains equal to or greater than 54\% (figure 5). Under these conditions, the structure was totally recrystallized with more homogeneous grains and boundaries that were not well defined. Some grains were deformed and oriented by flow direction.

Specimens deformed with a speed of 0.1 $\mathrm{mm} / \mathrm{s}$ and an engineering strain of $26 \%$ showed deformed grains like those in the material received. However they had better defined boundaries and some small equiaxial grains appeared. With an engineering strain of $62 \%$ the structure was completely recrystallized, which was more evident in regions with higher strains.

Under all these conditions at $850{ }^{\circ} \mathrm{C}$ the material showed good workability since no defects were observed.

\subsection{Tests at $950{ }^{\circ} \mathrm{C}$}

The samples deformed at this temperature showed the same microstructure under all different test conditions for speed and strain: globular and acicular $\alpha$ grains within a $\beta$-transformed matrix with equiaxial grains. In the regions where deformation was intense, the microstructure was elongated with the flow lines. In contrast to the microstructures deformed at other temperatures, at $950{ }^{\circ} \mathrm{C}$ grain boundaries were better defined, dynamic recrystallization was evident and grain refinement was also observed with speed of 0.1 and $1 \mathrm{~mm} / \mathrm{s}$ and engineering strains near. With the same strain and at lower speeds the microstructure was more homogeneous and the grains were coarsened (figure $6-$ a speed of $0.01 \mathrm{~mm} / \mathrm{s}$ and an engineering strain of 74\%). The alloy showed good workability at $950{ }^{\circ} \mathrm{C}$ : the highest engineering strains were reached at this temperature and no defects were present in the samples analysed.

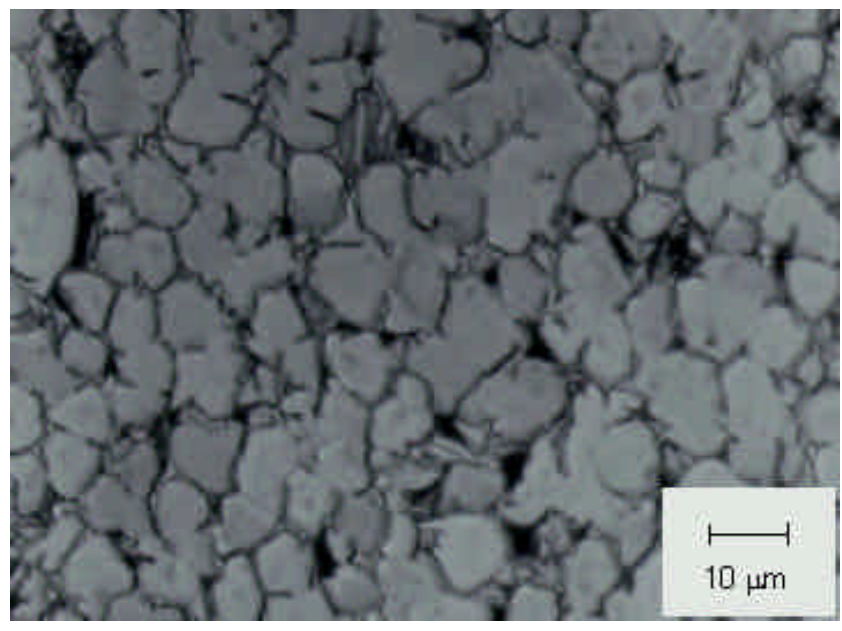

Fig. 6 Micrograph of deformed specimens at $950^{\circ} \mathrm{C}: \mathrm{v}=0.01 \mathrm{~mm} / \mathrm{s}$ and $\mathrm{e}=74 \%$.

\subsection{Tests at $1030{ }^{\circ} \mathrm{C}$}

Specimens deformed at this temperature (above $\alpha / \beta$ - $\beta$ transformation) showed the same microstructure for all strain speeds applied in the tests. The grains were not oriented in the flow direction and grain coarsening was intense and heterogeneous. Some grains showed coarsened regions of $\alpha$ phase. All samples showed the Widmanstäten microstructure [17]: acicular $\alpha$ grains surrounded by acicular $\beta$ grains, as shown in figure 7 .

When deformed at temperatures in the $\beta$ phase region, the $\alpha+\beta$ alloys like Ti-6Al-7Nb probably had their microstructures dynamically recovered [18]. That was apparently confirmed in this work by the absence of small grains and subgrains in all samples regardless of strain speed, because at this temperature the solid-state diffusion rates are increased allowing grains to be coalesced and coarsened.

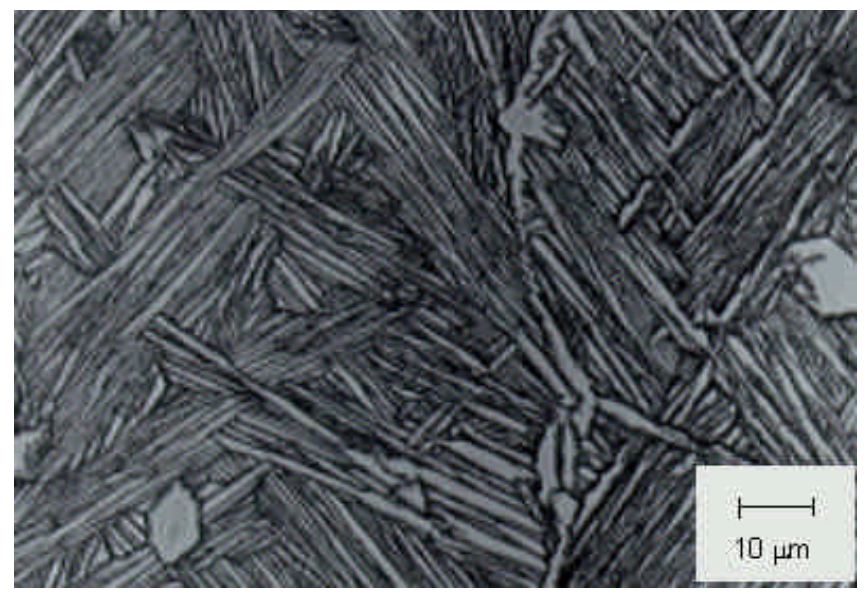

Fig. 7 Micrograph of deformed specimens at $1030{ }^{\circ} \mathrm{C}: \mathrm{v}=0.01 \mathrm{~mm} / \mathrm{s}$ and $\mathrm{e}=82 \%$. 
Samples deformed at temperatures above $950{ }^{\circ} \mathrm{C}$ without atmospheric treatment showed a light $\alpha$-case layer formed by the diffusion of oxygen. Apparently workability was not influenced since no cracks were observed. The thickness of the layer increased as temperature was increased, but it was relatively thin in comparison with the thickness of the sample (figure 8).

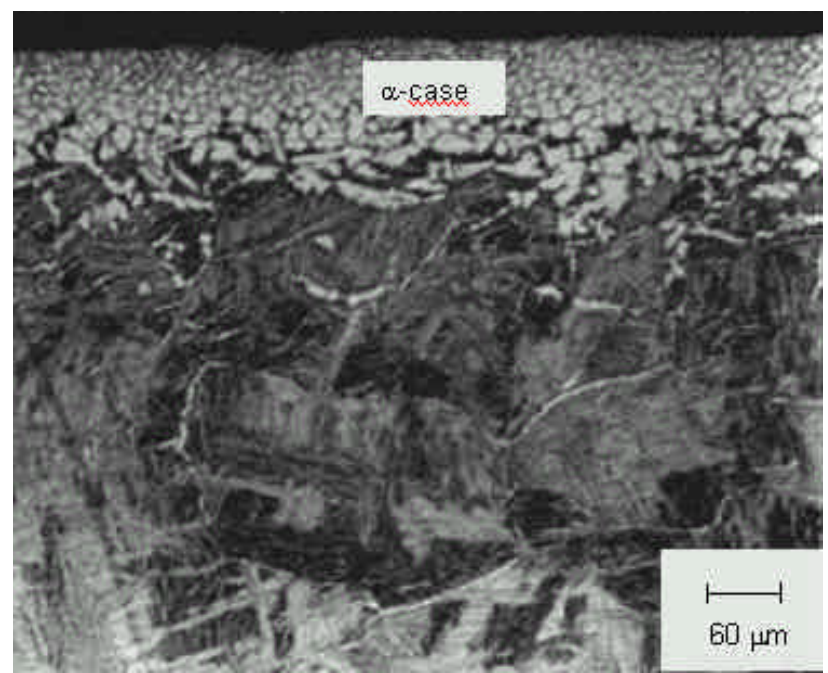

\subsection{Stress-strain behaviour and workability analysis}

Figures 9 to 12 present the stress-strain curves of the isothermal compression tests, with $\sigma_{\mathrm{e}}$ representing the engineering stress and $\sigma_{\mathrm{r}}$ representing the true stress. Deformation speeds are represented by the numbers beside $\sigma_{\mathrm{e}}$ and $\sigma_{\mathrm{r}}$.

True stress curves show that for all test temperatures, flow stress increased as deformation speed increased. The maximum strain obtained was limited by the nominal capacity of the equipment limited to $19600 \mathrm{~N}$.

Tests at $750{ }^{\circ} \mathrm{C}$ (figure 9) showed the highest yield stresses corresponding to a deformed and non-recrystallized microstructure, as shown in figure 4. Even with a deformation speed of 0.01 $\mathrm{mm} / \mathrm{s}$ the recrystallization was not preponderant and the flow stress was higher than for other temperatures (greater than $100 \mathrm{MPa}$ ). The constant flow stress observed in these curves, despite related to deformed microstructures, resulted from softening mechanisms governed by dynamic recovery [19].

Fig. 8 Micrograph of deformed specimen at

$1030{ }^{\circ} \mathrm{C}$ : light $\alpha$-case layer with thickness of $50 \mu \mathrm{m}$.

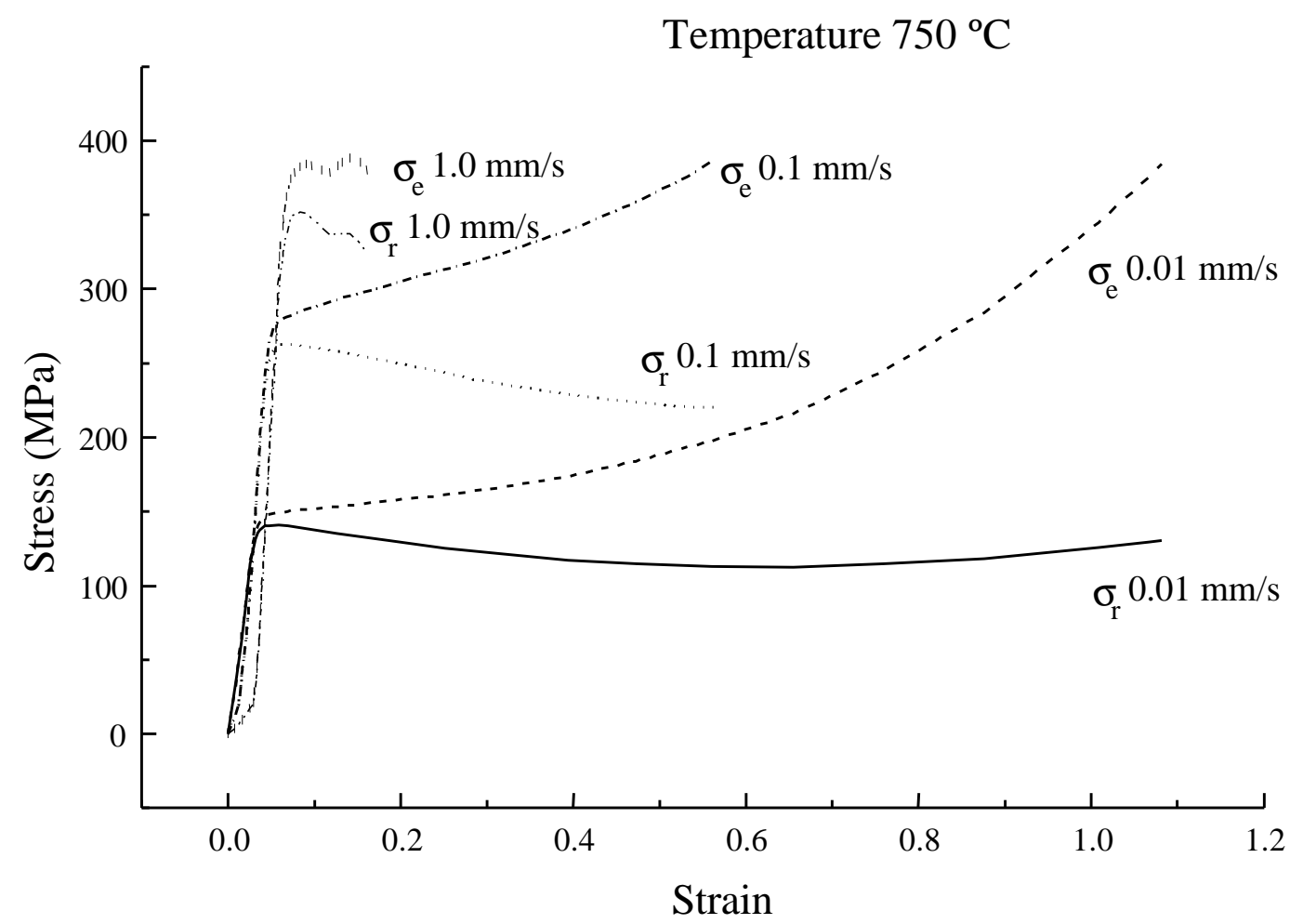

Fig. 9 Stress-strain curves of compression tests at $750{ }^{\circ} \mathrm{C}$ and different deformation speeds 


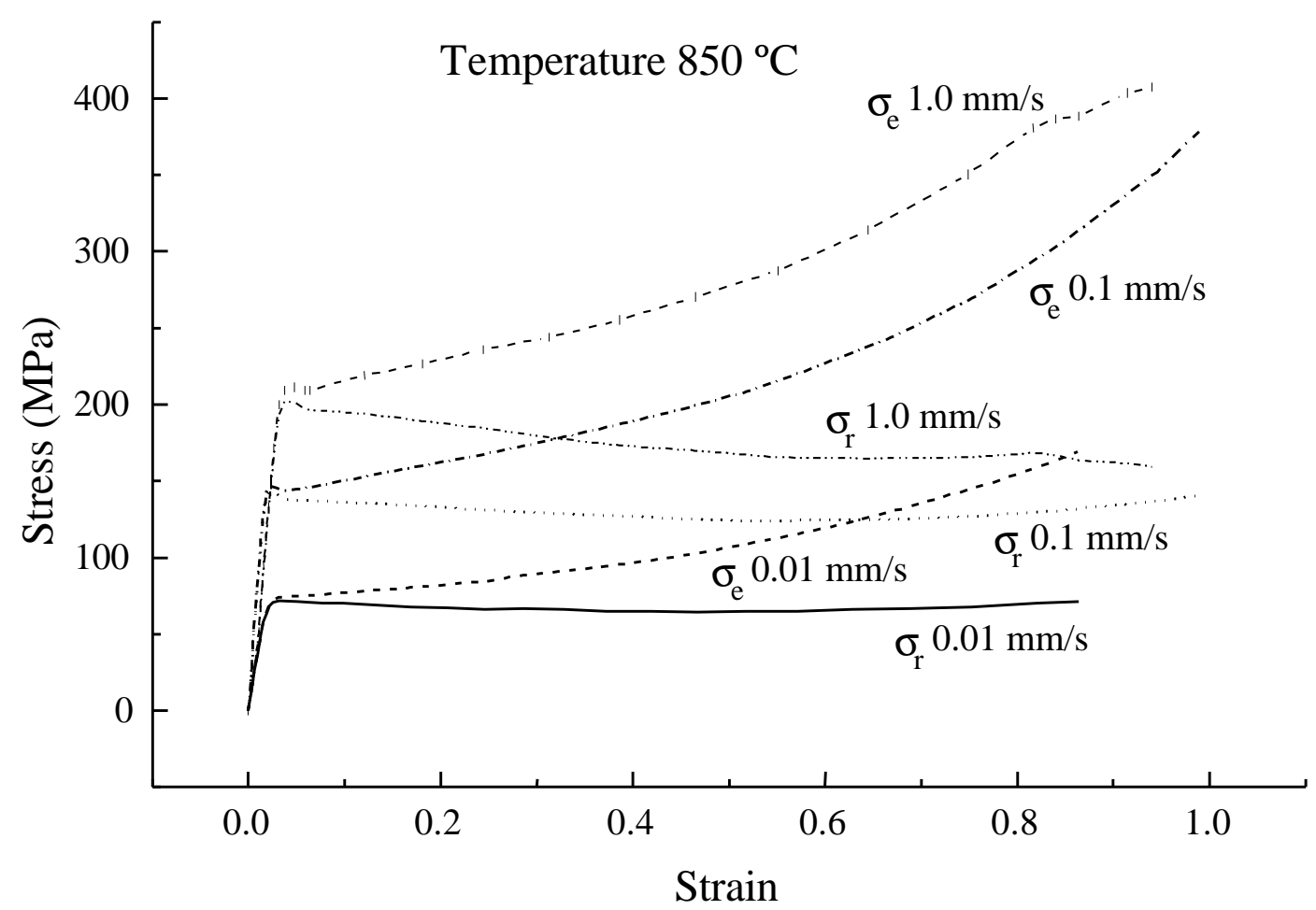

Fig. 10 Stress-strain curves of compression tests at $850^{\circ} \mathrm{C}$ and different deformation speeds

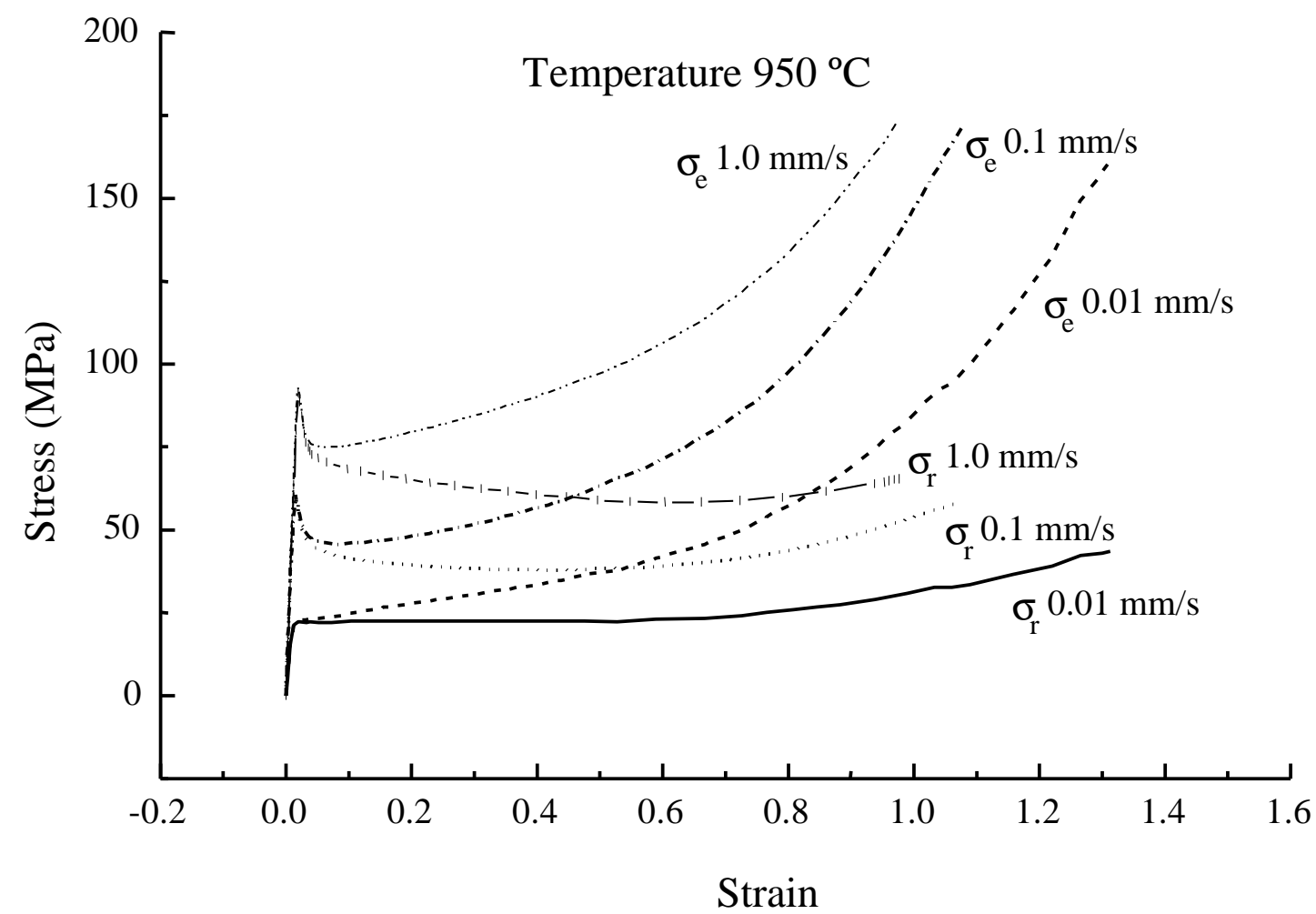

Fig. 11 Stress-strain curves of compression tests at $950{ }^{\circ} \mathrm{C}$ and different deformation speeds 


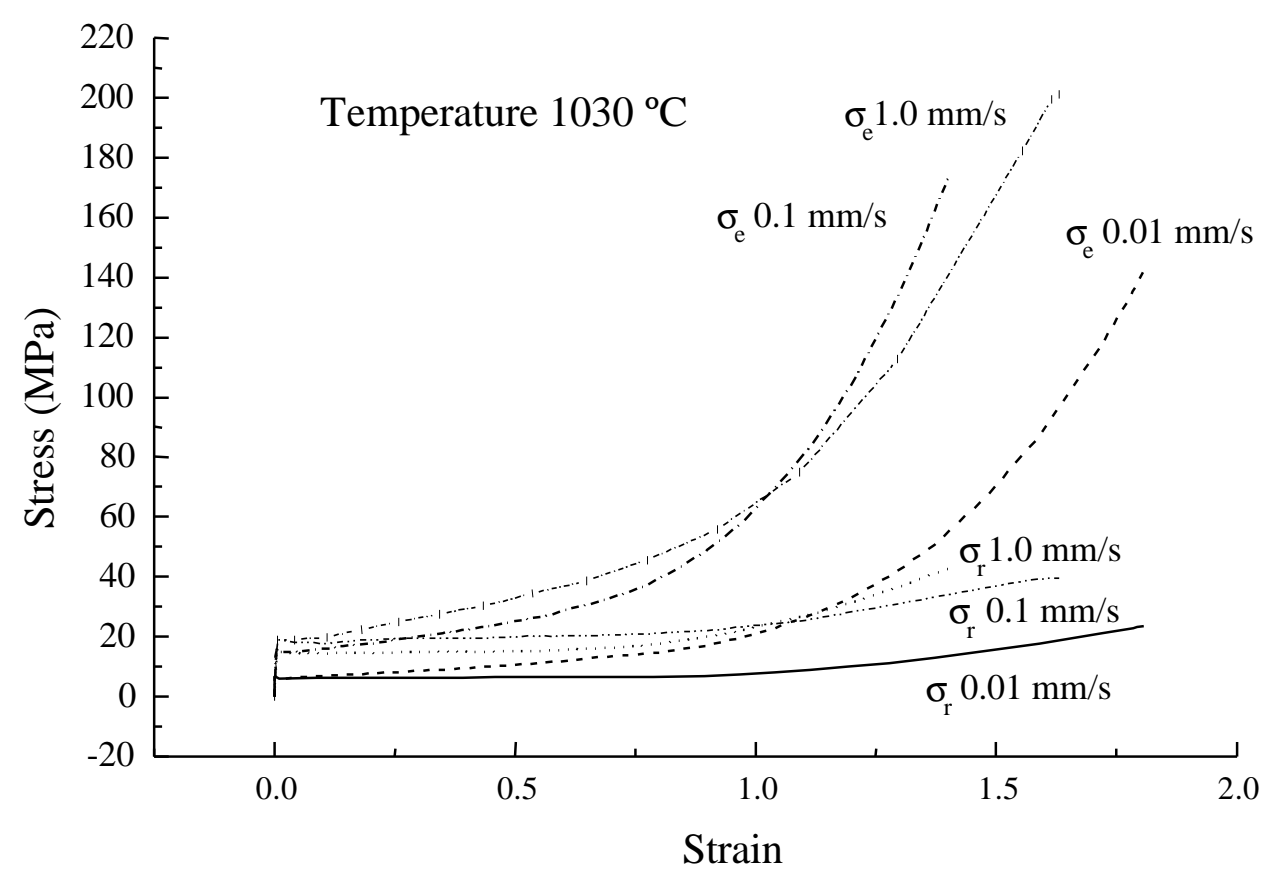

Fig. 12 Stress-strain curves of compression tests at $1030{ }^{\circ} \mathrm{C}$ and different deformation speeds

At $850{ }^{\circ} \mathrm{C}$ (figure 10) flow stress was reduced mainly for deformation speed of $0.01 \mathrm{~mm} / \mathrm{s}$ (near $75 \mathrm{MPa}$ ), representing a partially recrystallized microstructure with some regions presenting deformed and oriented grains (figure 5). The flow stress was still high if compared to those obtained at 950 and $1030{ }^{\circ} \mathrm{C}$ where recrystallization of the microstructure was complete.

Most of the curves presented a remarkable decrease in flow stress after yielding, mainly for speeds of 0.1 and $1.0 \mathrm{~mm} / \mathrm{s}$, as a result of softening mechanisms like dynamic recrystallization as related by other works [19,20,21] and confirmed when analysed with the correspondent microstructures.

After this "stress peak" flow stress remains constant under continuing deformation, since the temperature was not high enough to promote continuous dynamic recrystallization. In contrast, at 950 and a speed of $0.01 \mathrm{~mm} / \mathrm{s}$ (figure 11) and at $1030{ }^{\circ} \mathrm{C}$ for all speeds (figure 12), the flow stress remained almost constant till the end of the tests. These characteristics define a superplastic behaviour when the softening mechanisms overcome strainhardening effects.

This behaviour confirms the conclusions drawn about the microstructures, namely that dynamic recrystallization is dependent on compression temperature and on deformation as well.

The highest strains were obtained at 950 and $1030{ }^{\circ} \mathrm{C}$ with the lowest deformation speed $(0.01$ $\mathrm{mm} / \mathrm{s}$ ). These tests showed the highest workability since no defects were found in the specimens and minimum flow stresses were observed.

\section{CONCLUSIONS}

The following conclusions can be drawn from the results obtained in this work:

1. The microstructure and mechanical properties of isothermal forged Ti-6Al-7Nb are affected by temperature, deformation speed and strain. High temperatures, low speeds and large strains facilitate recrystallization in the $\alpha+\beta$ region. Inside the $\beta$ region, samples deformed during long periods at high temperatures and low strains showed a coarse microstructure.

2. Five different microstructures were found in sequence with increase in temperature: (1) deformed and oriented $\alpha$ grains within a $\beta$ transformed matrix softened by dynamic recovery; (2) recrystallized grains and isolated regions of $\beta$; (3) globular and acicular $\alpha$ grains within a $\beta$-transformed matrix, (4) the Widmanstätten microstructure, and finally, (5) a coarse $\alpha+\beta$ microstructure;

3. Three different softening mechanisms could be observed in the microstructures: (1) dynamic recovery and dynamic recrystallization at 750 and $850{ }^{\circ} \mathrm{C}$; (2) dynamic recrystallization and grain boundary sliding at $950{ }^{\circ} \mathrm{C}$, and (3) dynamic recovery with coalescence of grains at $1030{ }^{\circ} \mathrm{C}$; 
4. Under all the test conditions softening mechanisms equalised or overcame the strain hardening effect;

5. The influence of deformation speed on flow stress is reduced with an increase in work temperature;

6. To obtain an $\alpha+\beta$ microstructure with recrystallized and refined grains, the best conditions for isothermal forging are a temperature of $950{ }^{\circ} \mathrm{C}$ and a deformation speed of $0.01 \mathrm{~mm} / \mathrm{s}$;

7. The $\alpha$-case layer observed in samples deformed above $950{ }^{\circ} \mathrm{C}$ did not reduce the alloy's workability but should be prejudicial to forging quality and must be removed.

\section{ACKNOWLEDGEMENTS}

The authors wish to thank $\mathrm{CNPq}$ (Conselho Nacional de Desenvolvimento Científico e Tecnológico) and FAPESP (Fundação de Amparo à Pesquisa do Estado de São Paulo) for their financial support of this work.

\section{REFERENCES}

1 Semlitsch, M.F., Weber, H., Streicher and R.M., Schön, R. Joint replacement components made of hot-forged and surface-treated Ti-6Al-7Nb alloy. Biomaterials, 1992, 13 (11), pp. 781-788.

2 Semlitsch, M.F., Staub, F. and Weber, H. Development of a vital, high-strength titaniumaluminium-niobium alloy for surgical implants. Biological and Biomechanical Performance of Biomaterials, Proc. of the $5^{\text {th }}$ European Conf. on Biomaterials, 1986, pp. 69-74.

3 Semlitsch, M.F. Titanium alloys for hip joint replacements. Clinical Materials, 1987, 2, pp. 1-13.

4 Donachie, M.J. Jr. Introduction to Titanium and Titanium Alloys, Titanium and Titanium Alloys Source Book, ASM International, 1982.

5 Kobayashi, E., Wang, T.J., Doi, H., Yoneyama, T. and Hamanaka, H. Mechanical properties and corrosion resistance of Ti-6Al-7Nb alloy dental castings. Journal of Materials Science - Materials in Medicine, 1998, 9 (10), pp. 567-574.

6 Niinomi, M. Mechanical properties of biomedical titanium alloys. Materials Science and Engineering A - Structural Materials Properties Microstructure and Processing, 1998, 243 (1-2), pp. 231236.

7 Kuroda, D., Niinomi, M., Morinaga, M., Kato, Y. and Yashiro, T. Design and mechanical properties of new beta type titanium alloys for implant materials. Materials Science and Engineering A Structural Materials Properties Microstructure and Processing, 1998, 243 (1-2), pp. 244-249.
8 Schepp, P.P. Isothermal forging of titanium alloy surgical implants. Proceedings of the Technical Program from the 1990 International Conference, "Titanium 1990, Products and Applications", 1990, pp. 646-652.

9 Murray, J.L. The Al-Ti (aluminum-titanium) system. Phase diagrams of binary titanium alloys, ASM, 1987, pp. 12-24.

10 Murray, J.L. The Nb-Ti (niobium-titanium) system. Phase diagrams of binary titanium alloys, ASM, 1987, pp. 188-194.

11 Cope, M.T., Evetts, D.R. and Ridley, N. Post-forming tensile properties of superplastic Ti-6Al-4V alloy. Materials Science and Technology, 1986, 2, pp. 140-145.

12 IMI Titanium Ltd., IMI 367 - Product certificate, 1995.

13 Barbosa, P.F. Some aspects of the workability of Ti-6Al-7Nb alloy under isothermal forging conditions. Master's Thesis, 1996, State University of Campinas, Campinas, SP, Brazil.

14 Schey, J.A. Introduction to Manufacturing Processes, Second edition, McGraw-Hill Int. Editions, 1987, pp. 222-226.

15 Pragnell, P.B., Stobbs, W.M. and Withers, P.J., Considerations in the use of yield asymmetries for the analysis of internal stresses in metal matrix composites, Materials Science and Engineering, A159, 1992, pp. 51-63.

16 Raveh, A., Kimmel, G., Avni, R. and Grill, A. X-ray diffraction of plasma nitrided Ti-6Al-4V, Advances in X-ray analysis, Proc. Of the 38th Annual Conf. in Applications of X-Ray Analysis, 1983.

17 Prasad, Y.V.R.K. and Seshacharyulu, T. Processing maps for hot working of titanium alloys. Materials Science and Engineering A - Structural Materials Properties Microstructure and Processing, 1998, 243 (1-2), pp. 82-88.

18 Sheppard, T. and Norley, J. Deformation characteristics of Ti-6Al-4V. Materials Science Technology, 1988, 4, pp. 903-908.

19 Anderson, J.G. and Evans, R.W. Modelling flow stress evolution during elevated temperature deformation of two low carbon steels, Ironmaking and steelmaking, 23 (2), 1996, pp.130-135.

20 Luton, M.J. and Sellars, C.M. Dynamic recrystallization in nickel and nickel-iron alloys during high temperature deformation. Acta Metallurgica, 17, 1969, pp. 1033-1043.

21 Furu, T., Shercliff, H. R., Baxter G. J. and Sellars C. M. The influence of transient deformation conditions on recrystallization during thermomechanical processing of an Al-1\% Mg alloy, Acta Materialia, 47 (8), 1999, pp 2377-2389. 